Z. klin. Chem. u. klin. Biochem.

7. Jg., S. 96-100, Januar 1969

\title{
The handling and processing of data in a clinical chemical laboratory ${ }^{1}$
}

\author{
By M. HJELM \\ The Department of Clinical Chemistry, University Hospital, Uppsala, Sweden
}

(Eingegangen am 4. November 1968)

\section{Introduction}

During recent years the situation in many hospital laboratories has been characterized by

1. a tremendously increasing work load,

2. a pronounced shortage of personnel and

3. a need for a better standardization and a higher quality of the analyses performed.

The technical development has been of great importance in mastering this situation, especially on the analytical side; with a large number of instruments and machines for more or less automated analyses now available on the market.

The handling of data, however, has also proved to be a time-consuming procedure, which can often take as much as fifty per cent or more of the total time required for the analyses in the laboratory.

This handling of data includes at least:

1. Recording of the analyses requested and the identification of the samples.

2. Recording of primary values.

3. Calculation of final results for patients.

4. Calculation of some kind of quality-control values.

5. Production of different of laboratory lists.

6. A patient report to the ward.

Much time can also be saved by introducing systems for more or less automated data collection and data processing from simple devices, such as analogue-todigital converters and a printer or a computer, to mqre complex systems, to which many analyses channels are directly connected for data collection and calculations, ending with a print-out of the results directly in the ward (1). The type and scope of the system introduced must, to a considerable extent, depend on the actual structure and organization; the function of the hardware being to integrate different activities and to serve as an interface between different structures in the laboratory. Thus, it seems necessary to create interface solution with a high degree of flexibility and with the possibility of increasing stepwise the sophistication as the laboratory work becomes more developed on the analytical, data-collecting and calculating side. It also seems both desirable and necessary to define the requirements that the hardware must fulfill in the laboratory; and for the industries interested in the field, to keep in close contact with the clinical chemists for advice and suggestions.

1) Vortrag anläßlich der ILMAC, 11. September 1968, Basel.
Request formula and sample identification

It seems as if no ideal automated system exists, at present, for the requisition of analyses and the identification of samples. An interesting approach to the solution of the problem is, e. g. the IBM punch cards, in different modifications, for the requisition of samples, and the so-called IBM "stub cards" for the identification of samples. These solutions cannot be generally used, however, e. g. in large hospitals, because a) a considerable and, probably intractable, number of different types of punch cards would have to be intruduced, if requisition routines other than to the laboratory (clinical bacteriology, clinical physiology, X-ray, different departments for consultations, administration, kitchen etc.) are also included which is desirable; b) the stub card, as an identification tag, is restricted to chemical tests, and also presupposes reading devices which are connected only with a special type of analytical instruments. For a pilot study, however, the IBM system is most valuable.

A more general solution seems to involve the use of c) requisition formulas larger than punch cards, which can be read both manually and in an optical reader, and d) machine-readable labels, which can have a more general use in the hospital. In our laboratory, we have just succeded in developing a machine-readable, selfadhesive label ${ }^{2}$ ) with a number that defines not only the patient, who is given the same number on admission, and which he retains during his stay in the hospital, but also the tube. A stack of these labels are placed at the patient's bedside, and are used by the personnel who take the samples (cf fig. 1).

\section{The data-collecting system}

a) The data-collecting system must accept outputs from all types of instruments, in order to serve optimally as an interface between analysis and calculation.

b) The primary values must also be recorded by some kind of data logger, to permit manual calculations, if necessary, as is illustrated in figure 2. Electronic devices are surprisingly safe, when used for laboratory routine, but accidental breakdowns do occur.

Thus, an emergency routine, represented by the logger, must be included, and used to calculate the results manually when the data-collecting system or the computer does not function.

2) Constructed by Mr. B. Billås in our laboratory. 
Fig. 1

A principal scheme of a system for patient and sample identification
TURN TABLE OR READING STATION DATA COLLECTING

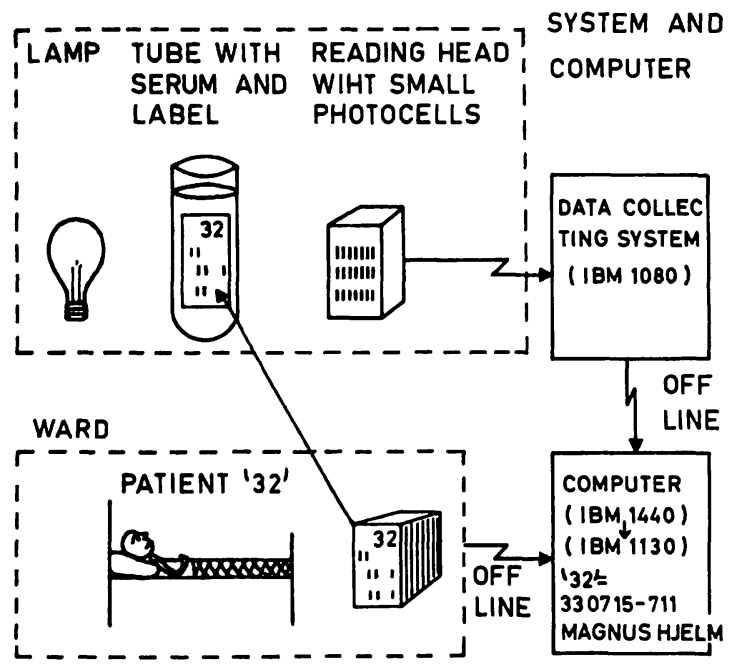

IN STRUMENTS

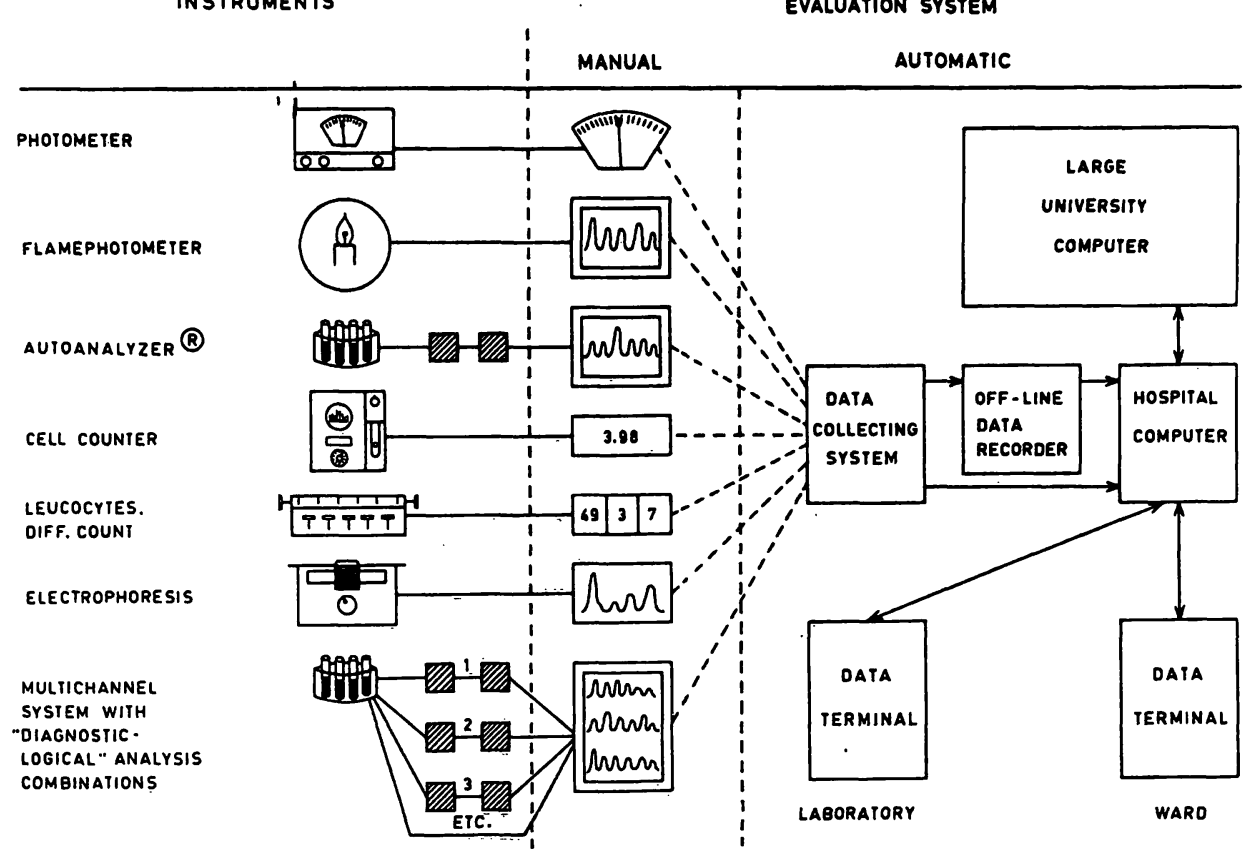

Fig. 2

All types of analytical equipment can be connected to the data collecting system but at the same time they display their output in the conventional manner. At least forty analysis channels can be connected to one data-collecting system c) The same analytical and data-collecting system should accept both routine and emergency samples, a demand which is closely connected with the possibility of finding machine-readable, sample-identification systems.

Off-line and on-line connections between the data-collecting system and the computer

The data-collecting system can principally be connected to the computer by means of, e. g. punch cards or paper tape, i. e. off line, or directly, i. e. on line: The advantages and disadvantages of these two types of connections have been much discussed during recent years. In my opinion, however, too much time has been devoted to this problem from a practical and technical point of view, e.g. the economic aspects have not received sufficiently consideration. (Cf. p. 102).

a) At present, the analytical instruments, and not the computer, form the rate-limiting step in integrated laboratory systems. b) Acute and routine samples can be analyzed simultaneously with both connections. This means that oriline solutions do not significantly decrease the real request-to-report time. Evidently, primary results introduced off line in the computer, can principally be printed out on line.

c) Data-collecting systems available on the market have an upper limit for the number of connected analysis channels; at present, economically reasonable systems contain about forty channels. The computer necessary to handle data from such a data-collecting system will always be larger with an on-line than with an off-line connection, as part of the memory will be constantly occupied by check routines, even at a low degree of cover. This also means that the cost per calculated value will be considerably higher with an on-line solutition.

d) The desirable number of analysis channels, to be connected to a data-collecting system, is already close to the practical value in many laboratories, and will 
probably exceed that figure in a few years. This will strongly influcnce the size of both the data-collecting systcm and the computer in on-line solutions. With the data-collecting systcm connected off line to the computer, additional data-collecting systems are simply introduced. The same computer is used to process, with different programs, the primary values from these different data-collecting systems. The time required to "empty" a computer and to feed in new primary values is often surprisingly short - e. g. about 90 seconds for the IBM 1130 computer. In this way, differentiated programs can be written for different types of analysis channels connected to different datacollecting systems, e. g. chemistry, haematology, immunology, research investigations, all of which may not be working the whole time. Thus, it seems possible to increase the number of analysis channels connected for automated recording of primary results up to $100-120$ - representing three data-collecting systems without increasing the size of the most expensive part of EDP systems ${ }^{1}$ ), the computer.

e) The parts, most sensitive to disturbances in integrated lahoratory systems still seem to the analytical instruments; and it often happens the primary values from one channel or another have to be checked and corrected for, e. g. "spikes" on the peaks. These corrections, even if relatively complex, are easily made, if the data-collecting system is connected off-line to the computer. This simply implies changing manually, in the stack of result cards, those values which have to be punching a few new cards. The possibility of including these operations, which vary from day to day, in a computer programme and of covering with this programme all possibilities that may arise on the analytical side, seems to be limited both for practical and for economic reasons. Thus also in this respect, the offline solution seems to have definite advantages at present. f) It may also pointed out that, the real advantage of an on-line system, i.e. the possibility of empolying the computer for a direct and automatic control of the individual analysis channels, e. g. by changing a pump velocity, a slit width etc., cannot be used with the present equipment ordinarily privided in the clinical chemical laboratories.

\section{Quality control of chemical analyses}

The possibility of applying different types of statistical and mathematical methods for calculating patient, and scrum control, values, is substantially increased if a computer can be used. Theoretically, these values can also be calculated manually. In practice, however, this soon becomes a time consuming procedure, even with a relatively modest number of analysis channels. Here, a computer can be employed to save time for both the clinical chemist and the technician. The accuracy of the calculations will be the same whether these are made by a computer or by manual calculation.

1) Abbrevialion: EDP-systcm = Electronic Data Proccssing system.

\section{Laboratory lists and patient reports}

The great flexibility available for the production of different types of laboratory lists and patient reports of different types, from values stored in a computer, is obvious. In this connection it may be pointed out that the design of the different reports to the ward cannot be a task solely for the clinical chemist, but is a matter of common interest for the clinical chemist and the physicians in the other departments' of the hospital.

Handling of chemical data at the University Hospital in Uppsala

In Uppsala, clinical chemistry is organized as one unit, with a central laboratory and nine peripherally located clinic laboratories. This organization serves all patients, both from the wards and from the different outpatient departments - in 1967 about 35,000 inpatients and 150,000 outpatients.

In the same year about one million analyses were performed including about 250,000 haematological and 150,000 qualitative tests mainly on urine samples.

The staff consists of six clinical chemists, two chemical engineers, one electronic computing engineer, forty-five technical assistens or laboratory nurses, thirty-five aids, and three clerks.

\section{Present system for routine analyses}

Requests are still made on handwritten forms, cf. p. 96. All capillary samples, and most of the venous blood samples are taken by the laboratory personnel and brought to the central laboratory and the clinic laboratories. Urine samples are sent by the general hospital transport system. A pneumatic-tube system is also available for urgent tests. The samples are prepared in different ways in the laboratory, centrifuged, and serum or plasma pipetted into clean tubes etc. The final specimen is given a sequential number and the same number is written on the request. Thus, at present, a system with sequential numbers is used to identify the samples. An optical, sample-identification system is, as previously mentioned, being tested. The réquest and the sample are then handled as follows (cf also fig. 3).

\section{Request cards}

The information on the handwritten documents is manually punched into punch cards in the laboratory. These cards are read into the computer off line.

\section{Result cards}

In most cases, the instruments used for reading the primary results are connected to a data-collecting system. This system - at present a slightly modified IBM 1080 system - consists of the following parts: The instruments are connected to recorders, where the primary results appear, e. g. as peaks. A slide wire is enclosed in the recorders taking the analogous voltage from the potentiometer of the recorder. The highest analogue voltage induced by the peak on the recorder 


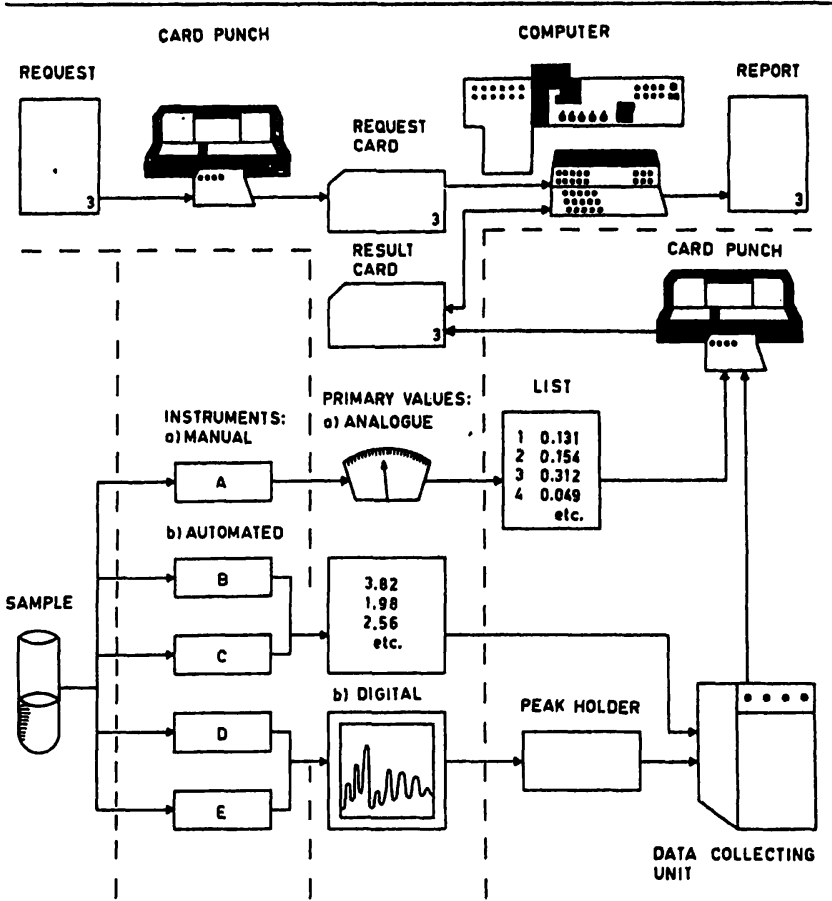

Fig. 3

Current system for the automated handling of laboratory data in the laboratory

is stored in a peak bolder, and automatically converted into a digital number in an analogue-to-digital converter at suitable time intervals. The digital values for standard solutions, patient samples and control samples are automatically punched into punch cards, result cards. These cards are read into the computer off-line.

In the computer (at present IBM 1440; IBM 1130 being under test), programs handle requisition cards and result cards in different ways. Since 1961 an increasing number of analysis channels have been connected to different types of data-collecting systems. In our present routine the following instruments are connected to the data-collecting system for automatic recording of primary results on cards:

a) A five-channel system for serum and urine electrolytes $(\mathrm{Na}, \mathrm{K}, \mathrm{Ca}, \mathrm{Cl})$.

b) A three-channel system for serum bilirubin, thymol, and alkaline phosphatase.

c) A two-channel system for serum transaminases (GOT, GPT).

d) A two-channel system for serum and urine glucose and galactose.

e) A two-channel system for serum iron and serum haemoglobin.

f) A two-channel system for serum and urine creatinine.

g) A one-channel system for serum protein-bound iodine.

h) A one-channel system for serum albumin.

i) A one-channel system for serum haptoglobin.

j) A one-channel system for serum uric acid.

k) A one-channel system for serum and urine phosphate.

This system is currently used for about 400,000 analyses per year. The figure represents about forty per cent of the total number of analyses including haemato-

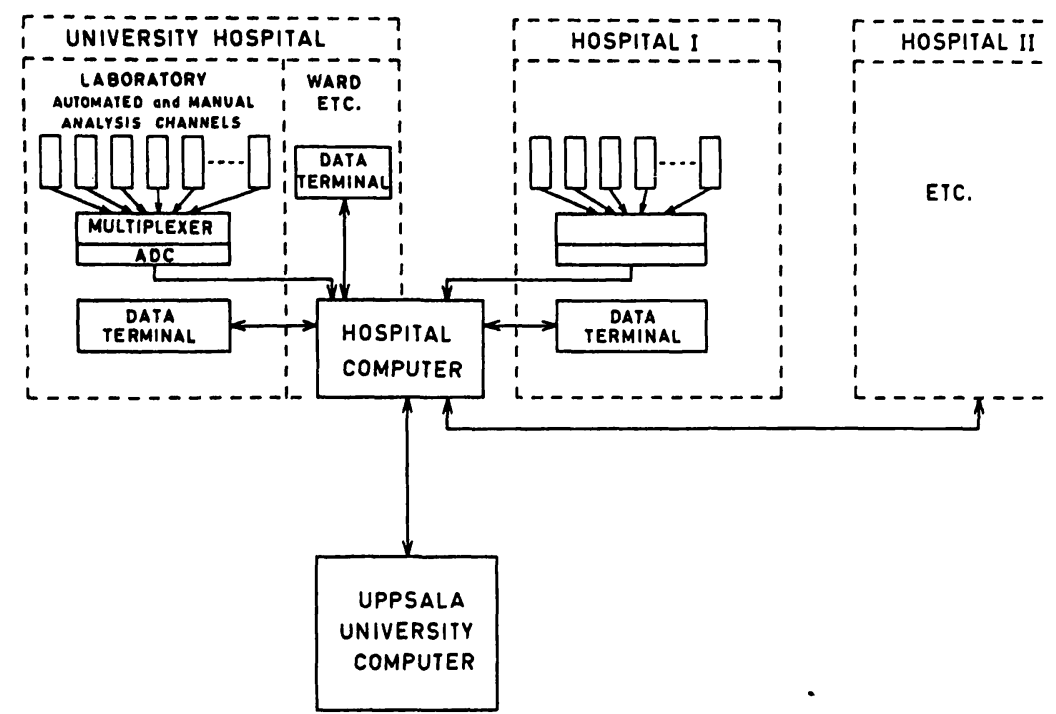

Fig. 4

Current system for the automated handling of laboratory data between hospital laboratories

logy and qualitative urine tests or about eighty per cent of the analyses performed in the central laboratory.

\section{Calculations ${ }^{1}$ )}

The following calculations described in detail elsewhere $(2,3)$ are automatically made:

a) Sample-interaction coefficients (2) to correct the

"tailing" of samples in the continuous flow systems,

b) First and second order standard curves,

c) Daily control sample values,

d) Cumulative sum charts for a continuous follow up of methods (4),

e) Patient values with a statistical evaluation,

Use of the system in other hospital laboratories The same system and the same program are used at present by two other hospital laboratories in the same region as Uppsala and will be used by three other hospitals in the same area. In these hospitals a card punch, the data-collecting system, and a card reader will be introduced in a first step. Request and result card are telegraphed to Uppsala, where the cards are processed (cf fig. 4). When the personnel has been trained, the computer will be installed in a second step. In general, this development will, moreover, undoubtedly increase the possibility of standardizing the handling of laboratory data also in a geographic area, and promote, e. g. a decentralized centralization of the work load between laboratories, $i$. e. to enable the laboratories to specialize in particular types of techniques and methods.

1) A programme for these calculations, called ' $\mathrm{Cl} . \mathrm{S}$, Data processing system for clinical chemical laboratories', and the different txpes of outprints have been designed by the central laboratories in Hudiksvall (Head: $\AA$. Holmgård), Sundsvall (Head: $\Lambda$. HAMpext), and Uppsala in collaboration with the University Computer Center in Uppsala (Head: W. SchNeIDER) and IBM, Sweden. 


\section{Economic aspects}

The average cost for one printed value, after automatic recording of the primary value, the calculation of a final result with a statistical evaluation and different outprints, is, at present, about 0.4 Swedish crowns. This represents about ten per cent of the average cost

\begin{tabular}{|c|c|c|}
\hline \multicolumn{3}{|c|}{$\begin{array}{l}\text { Tab. } 1 \\
\text { Estimation of savings during a five year Period 1962-1967 } \\
\text { (in Swedish Crowns) }\end{array}$} \\
\hline \multicolumn{3}{|l|}{ Savings } \\
\hline \multicolumn{3}{|l|}{$\begin{array}{l}\text { Increase in number of analyses about } \\
100 \% / 5 \text { years. This is estimated to } \\
\text { correspond to an increase in work load } \\
\text { of } 75 \% / 5 \text { years or } 12 \% / y e a r \text {. Salaries } \\
\text { for laboratory assistents and aids } \\
1962 / 631,200,000 \text {. }\end{array}$} \\
\hline $\begin{array}{l}\text { Estimated increase in salaries ( } 12 \% / \text { year }) \\
\text { during the } 5 \text { years period of not } \\
\text { automated }\end{array}$ & $2,496,000$ & \\
\hline $\begin{array}{l}\text { Staff increased about } 4 \% / \text { year. Corre- } \\
\text { sponds to a total increase in salaries } \\
\text { during these } 5 \text { years (adjusted to the } \\
\text { salary level of } 1962 / 63 \text { ) }\end{array}$ & $\underline{758,000}$ & $1,738,000$ \\
\hline Investments & & \\
\hline $\begin{array}{l}\text { 1. Automated analytical systems } \\
\text { 2. Computer time, rent for punches etc. }\end{array}$ & $\begin{array}{l}750,000 \\
550,000 \\
\end{array}$ & $1,300,000$ \\
\hline Gain & & 438,000 \\
\hline
\end{tabular}

for a chemical analysis, which is between three and four Swedish crowns, and is about the same price as that of the dispensible cannula and tube used in taking blood samples. An estimate of the saving obtained by introducing EDP and other measures to rationalize the laboratory work, is given in table 1 . In this table a saving of about 400,000 Swedish crowns has been estimated for a five year period. Consequently, it seems justifiable to state, that the system introduced has, at least, not increased the cost, despite the obvious medical and practical advantages.

\section{General conclusions}

The automated handling of data in a clinical chemical laboratory has significantly contributed (a) to increase the per capita working capacity by about 100 per cent in a fiver-year period, by reducing the clerical work to a minimum; and (b) to introduce a daily standardized quality control currently for about 400,000 determinations per year, representing about twentyfive analytical methods. The costs must be considered both acceptable and reasonable.

\title{
Referencecs
}

1. HJelar, M., W. Schneider, J. C. Vuille and G. Wallenius, Automated Acquisition, Processing and Communication of Laboratory Data in a Hospital. World Hospitals: l'Hospital le Monde 3, 174 (1967). - 2. HJELM, M., Quality Control of Automated Analytical Systems in Clincal Chemistry. This journal, to be published. - 3. CLS-Dataprocessing system for clinical chemical laboratories. Uppsala University Hospital, Uppsala Üniversity Datacenter, Uppsala, Sweden and IBM International Medical Support Center, Stockholm, Sweden (1968). - 4. Woob'ward, R. H. and P. L. GoldsMrth, Cumulative sum techniqués. I. C. I. Monograph No 3, Oliver and Boyd Ltd, Edinburgh and London (1964). University Hospital Uppsala, Sweden

Z. klin. Chem. u. klin. Biochem.

7. Jg., S. 100-104, Januar 1969

Round Table-Diskussion

\section{Round Table-Diskussion}

\author{
Bearbeitung: R. H. H. RICHTER, Bern
}

(Eingegangen am 25. November 1968)

Moderator: Prof. Dr. R. RichterICH, Bern

Teilnehmer: Dr. T. BRECHBÜHLER, Basel

PD Dr. Dr. H. Bütrner, Kiel

Dr. J. Bierens de HaAN, Genf
Dr. M. HJeLM, Uppsala

Dr. R. H. H. RICHTER, Bern

Dr. M. Rorh, Genf

PD Dr. Dr. D. Stamm, München

\section{Prof. Richterich}

Sehr geehrte Damen und Herren!

Ich habe keine Fragen erhalten; man könnte daraus entnehmen, daß heute nachmittag alles so klar war, daß für die gesamte Automation und Datenverarbeitung gar keine Probleme mehr übrigbleiben. Das zwingt mich, irgendwelche Fragen selbst hier zur Diskussion zu stellen, und ich möchte als erstes ein konkretes Problem diskutieren: Was macht man, wenn z. B. in Bern um
5 Uhr abends alle Labordaten im Rechenzentrum der Universität liegen und der Computer nicht fựktioniert? Ich möchte vielleicht Dr. Hjelm fragen. How do you solve the problem, when your computer breakes down?

\section{Dr. Hjelm}

A manual evaluation system is included in the system for this situation. This system consists of the recorders or digital printers, where the primary values always are registered before they enter into the data collecting unit. 